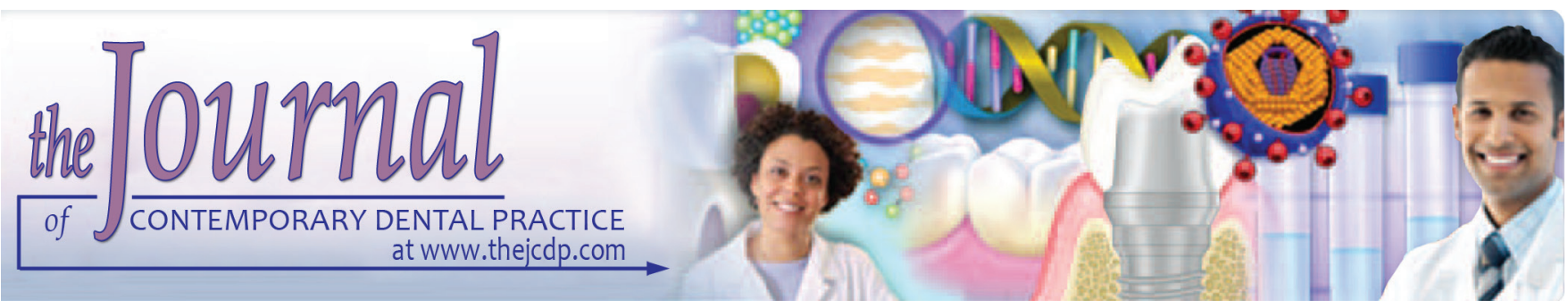

\title{
Correlation between Innercanthal Distance and Mesiodistal Width of Maxillary Anterior Teeth in a Thrissur, Kerala, India, Population
}

${ }^{1}$ George Attokaran, ${ }^{2}$ Kamalakanth Shenoy

\begin{abstract}
Background: Selecting and replacing missing teeth to natural proportions and esthetic preference of a patient in the absence of pre-extraction records is a very challenging task. Although facial analysis and proportions are well discussed in many populations, none exists for the Thrissur, Kerala, population. A prosthodontic rehabilitation for Kerala patients relying on other racial norms may result in dissonant facial proportions. Therefore, the purpose of this study was (1) to evaluate the validity of innercanthal distance as a guide in determining the mesiodistal dimension of six maxillary anterior teeth in a selected Malayalee population in the Thrissur Municipal Corporation area; (2) to check whether innercanthal distance undergoes dynamic changes over time as a result of aging; and (3) to evaluate whether there is a gender difference in the analyzed mean facial and dental proportions in this population.
\end{abstract}

Materials and methods: The study was conducted on 1,200 subjects in the Thrissur Municipal Corporation area. From five wards, 240 subjects were selected, out of which 120 were from the 18 to 25 years age group and 120 from the 40 to 50 years age group. Sixty males and females were selected from each group. The innercanthal distance was measured using a Digital Vernier Caliper, and alginate impressions were made to evaluate the size of maxillary anteriors. The data was analyzed statistically.

Results: The study showed that there is a high statistical significance between the innercanthal distance and the mesiodistal width of six maxillary anterior teeth in females $(p<0.01)$ and no significance in males. There was also dynamic changes in the

${ }^{1}$ Department of Prosthodontics, PSM College of Dental Science and Research, Thrissur, Kerala, India

${ }^{2}$ Department of Prosthodontics, Yenepoya Dental College Yenepoya University, Derlakatte, Mangaluru, Karnataka,India

Corresponding Author: George Attokaran, Professor Department of Prosthodontics, PSM College of Dental Science and Research, Thrissur, Kerala, India, Phone: +919846123660 e-mail: pritigeorgeattos@gmail.com innercanthal dimension and the mesiodistal width of maxillary anteriors with increase in age $(p<0.001)$. The difference in the mean of innercanthal distance between the genders was highly statistically significant, but no significance was found between the genders in the mesiodistal width of maxillary anteriors.

Conclusion: Within the population evaluated, there was a high statistical significance in females between the innercanthal distance and the mesiodistal width of six maxillary anterior teeth, but not for males. Innercanthal dimension was found to undergo dynamic changes as age increases in both males and females, and it was much higher in males than in females. There was no statistical significance in the comparative evaluation of mesiodistal width of maxillary anteriors of males and females in the study.

Clinical significance: Teeth selection is a critical step in determining the outcome of successful prosthodontic treatment. No definite guidelines for the selection of maxillary anterior teeth pertaining to the Thrissur, Kerala, population exist. A prosthodontic rehabilitation of Thrissur, Kerala, patients relying on other racial norms will result in dissonant facial proportions. In selecting maxillary anterior teeth, the knowledge of racial norms will help specify certain esthetic and functional modifications in treatment plans, which might be specific to each group. Therefore, there remains an unquestionable need for a scientific and reliable method for maxillary anterior teeth selection, which can be applied on this group of Indian population.

Keywords: Facial and dental proportion, Innercanthal dimension, Maxillary anterior teeth, Mesiodistal width.

How to cite this article: Attokaran G, Shenoy K. Correlation between Innercanthal Distance and Mesiodistal Width of Maxillary Anterior Teeth in a Thrissur, Kerala, India, Population. J Contemp Dent Pract 2016;17(5):382-387.

Source of support: Nil

Conflict of interest: None

\section{INTRODUCTION}

The face is the most expressive part of the human body as it determines an individual's social acceptance. Maxillary 
anteriors play a significant role in contributing to factors responsible for a pleasing appearance.

The patient who wears a prosthesis would want it to appear similar to natural teeth. Esthetic restoration of the edentulous patient has an important psychological effect. It improves self-esteem and self-confidence of a patient and therefore is an important part of the oral rehabilitation treatment.

Selecting and aligning replacement teeth to natural proportions facilitates a natural and esthetic appearance. Providing artificial maxillary teeth that closely resemble the patient's missing natural teeth can pose a significant challenge to the dentist. Increasing esthetic awareness and expectations of today's patients make this challenge more difficult. Improper selection of artificial teeth can result in patient rejection of otherwise well-constructed, comfortable, and efficient prosthesis.

Pre-extraction records are reliable guides for selection of teeth, and clues gained from natural dentition can be of help in achieving an individual and attractive restoration for a patient. ${ }^{1}$ When no pre-extraction records of natural teeth, such as casts or photographs are available, selecting proper anterior teeth can be difficult. ${ }^{2}$

Dental companies have tried to simplify tooth selection by supplying dentists with many molds, guides, shade guides, folders, and pamphlets. ${ }^{3}$ Yet the empirical nature of the process remains as none of these guidelines have been validated across racial profiles. ${ }^{4}$ Almost all tooth selection guides have been derived from Caucasian population. ${ }^{5}$

Parameters of the face that are closer to the alveolar and dental areas show greatest difference between racial and ethnic groups. In treatment, it is important to determine the possible contributing factors - instituting care according to the individual conditions. Thus, diagnosis and treatment plans should not be interchanged from one racial group to another without consideration of racial norms of each group. ${ }^{6}$ The information gathered by looking at racial norms can be significant in the practice of prosthodontics. 7

During denture fabrication, the length of upper lips at rest and the smile design can be a reliable guide to estimate the height of maxillary anterior teeth. However, no reliable anatomic parameters are available to select the adequate width of maxillary anterior teeth. ${ }^{8}$

Maxillary anterior teeth should be in proportion to facial morphology, and several anatomic measurements have been proposed to aid in determining the correct size of anterior teeth, intercommissural width, ${ }^{9}$ bizygomatic width, ${ }^{10}$ interpupillary distance, inter-pterygomaxillary notch distance, ${ }^{11}$ the center of incisive papilla, ${ }^{12}$ inter-alar width, and innercanthal distance. ${ }^{13}$

In direct contrast with developed countries, a significant portion of a general dentist's practice in India is made up of prosthodontic rehabilitation. Trends in population and aging suggest that this need is bound to remain a sizeable challenge in the near future. This study was planned on 1,200 subjects in the Thrissur Municipal Corporation area. The objectives of the study were (1) to evaluate the validity of innercanthal distance as a guide in determining the mesiodistal dimension of six maxillary anterior teeth; (2) to check whether innercanthal distance undergoes changes as a result of aging; and (3) to determine whether there is a difference between males and females in the analyzed facial and dental proportions in this population.

The study was conducted on two age groups -18 to 25 years of age and 40 to 50 years of age - to check whether this anthropometric soft tissue land mark undergoes dynamic changes as age increases.

In selection of maxillary anterior teeth, the knowledge of racial norms will help specify certain esthetic and functional modifications in treatment plans, which might be specific to each group. Therefore, there remains an unquestionable need for a scientific and reliable method for maxillary anterior teeth selection, which can be applied on this group of Indian population.

\section{MATERIALS AND METHODS}

The study was conducted in the Thrissur Municipal Corporation with an area of $101.42 \mathrm{~km}^{2}$ and a population of 3,17,526. ${ }^{14}$ The Thrissur Municipal Corporation has 50 wards, out of which five wards were selected at random. With 95\% confidence interval and $85 \%$ power, a sample size of 1,200 was selected. From each of the five wards, 240 subjects were selected, of which 120 were in the 18 to 25 years age group and the other 120 were from the 40 to 50 years age group. Equal number of males and females $(n=60)$ were selected from each age group.

The subjects were selected by a house-to-house survey, and they were requested to visit a nearby dental clinic in their ward for data collection. The data collection was continued in each ward till the required number of samples were obtained.

A request letter for participation in the study was made in both English and Malayalam, and an informed consent letter to be signed by the subjects was also made available in both the languages. The study was presented before the ethics committee of PSM Dental College, Thrissur, and consent was obtained.

\section{Subject Selection Criteria}

\section{Inclusion Criteria}

- Subjects with full complement of natural teeth, which are fully erupted 
- No proximal restorations on the distal surface of maxillary canines that affect the width of anterior teeth

- Teeth with intact contact points

- Absence of crowding of teeth

- Subjects who were free from facial abnormality

- Subjects with Kerala ancestors, at least from two previous generations (from both the father's and mother's side).

\section{Exclusion Criteria}

- Subjects who had undergone maxillary anterior teeth size alterations

- Subjects with spacing of maxillary anterior teeth

- Subjects with gingival hyperplasia or gingival recession

- Subjects who had undergone orthodontic treatment

- Subjects who had undergone prosthodontic treatment like crowns or fixed partial dentures

- Subjects who had tooth agenesis

- Subjects who had undergone facial surgery.

During data collection, a unique ID was given and each ward was denoted the numbers I, II, III, IV, and V. Subjects were in the age group 18 to 25 years and 40 to 50 years. Males were denoted as " $\mathrm{M}$ " and females were denoted as " $\mathrm{F}$ ".

\section{Determination of Innercanthal Distance}

The subject was seated in an upright position with the head held steadily. Innercanthal distance was measured from one medial angle to the other of palpebral fissures using a Digital Vernier Caliper (Digimatic Caliper, Mitutoyo Corporation, Japan). Each measurement was a mean of three readings. All readings were carried out by the same examiner to avoid interexaminer variability.

\section{Impression Making}

Upper alginate (tropicalgin Zhermack, Italy) dentulous impressions of the subjects were made using the correct water-powder ratio. The casts (type III dental stone, Kalabhai) were poured immediately. Casts were used to measure the mesiodistal width of six anterior teeth as on a curve (as they are on a dental arch). A flexible millimeter ruler was used to measure on a curve the distances between the distal surfaces of maxillary canines from the region of proximal contacts. For the sake of consistency, the same examiner made all the impressions and performed all the measurements. The measurements were made three times. From these three results, a mean was calculated to establish the consistency of the measurements. The values were collected and analyzed statistically.

The collected data were analyzed with the help of Statistical Package for the Social Sciences (SPSS) Version 17.0. The normal values were obtained by estimating the mean, standard deviation, and $95 \%$ confidence intervals. Comparison between the age groups and gender were estimated by using the Student's t test. Multivariate analysis was done for combined effects. A $p<0.05$ was considered as significant.

\section{RESULTS}

From a sample size of 1,200 , a total of 240 subjects were selected from each of the five wards. Out of this, 120 belonged to the 18 to 25 years age group and 120 to the 40 to 50 years age group. From each age group, out of 120 subjects, 60 males and 60 females were selected.

In Table 1, the mean values with standard deviation of innercanthal distance and mesiodistal width of six maxillary anterior for both males and females in the age groups 18 to 25 and 40 to 50 for all the five wards are given.

In the 1,200 subjects, the mean innercanthal distance was $31.90 \pm 0.91$ and the mean mesiodistal width of six maxillary anterior teeth was $57.11 \pm 3.31$ (Table 2). This was found to be highly statistically significant $(\mathrm{p}<0.001)$. In gender-wise correlation in females (600 subjects), the mean innercanthal distance was $31.51 \pm 0.77$ and the mean mesiodistal width of six maxillary anterior teeth was $54.78 \pm 1.26$. This was found to be highly significant $(\mathrm{r}=0.130$ and $\mathrm{p}<0.01)$. However, in males (600 subjects), the mean innercanthal distance was $32.28 \pm 0.87$ and the mean mesiodistal width of six maxillary anterior teeth was $59.44 \pm 3.06$. This was found to be not significant $(\mathrm{r}=0.036$ and $\mathrm{p}=0.377)$.

In the age group-wise correlation, in the 18 to 25 age group (600 subjects), the mean innercanthal distance was $31.405 \pm 0.72$ and the mean mesiodistal width of six maxillary anterior teeth was $56.78 \pm 3.06$. This was found to be highly significant $(r=0.281$ and $p<0.001)$. In the 40 to 50 age group (600 subjects), the mean innercanthal distance was $32.39 \pm 0.80$ and the mean mesiodistal width of six maxillary anterior teeth was $57.43 \pm 3.50$. This was found to be highly significant $(r=0.379$ and $p<0.001)$.

Comparative age group-wise evaluation of the mean innercanthal distance and the mean mesiodistal width of six maxillary anteriors showed that these two parameters in this study showed an increase with increase in age, and this was extremely statistically significant $(\mathrm{p}<0.001)$ (Table 3, Graphs 1A and B).

Comparison of the mean innercanthal distance between males and females showed the results $32.28 \pm 0.87$ and $31.52 \pm 0.77$ respectively, and this was found to be extremely statistically significant $(\mathrm{p}<0.001)$. However, no statistical significance was found between males and females while comparing the mesiodistal width of six maxillary anterior teeth $(p=0.97)$, which was $59.44 \pm 3.06$ and $54.77 \pm 1.26$ respectively (Table 4 , Graphs $2 \mathrm{~A}$ and B). 
Correlation between Innercanthal Distance and Mesiodistal Width of Maxillary Anterior Teeth

Table 1: Mean values with standard deviation of innercanthal distance and mesiodistal width of six maxillary anterior teeth for both males and females in the age groups 18 to 25 and 40 to 50 for all the five wards

\begin{tabular}{|c|c|c|c|c|c|c|}
\hline \multirow[b]{2}{*}{ Age category ( $n=600$ each) } & \multirow[b]{2}{*}{ Ward ( $n=120$ each) } & \multirow[b]{2}{*}{$\begin{array}{l}\text { Sex }(n=60 \\
\text { each })\end{array}$} & \multicolumn{2}{|c|}{ Innercanthal distance } & \multicolumn{2}{|c|}{$\begin{array}{l}\text { Mesiodistal width of } 6 \\
\text { maxillary anterior teeth }\end{array}$} \\
\hline & & & Mean & $\begin{array}{l}\text { Standard } \\
\text { deviation }\end{array}$ & Mean & $\begin{array}{l}\text { Standard } \\
\text { deviation }\end{array}$ \\
\hline \multirow[t]{10}{*}{18 to 25 years } & Ward-1 & Male & 31.89 & 0.51 & 57.87 & 1.52 \\
\hline & & Female & 30.87 & 0.59 & 54.25 & 1.08 \\
\hline & Ward-2 & Male & 31.41 & 0.51 & 58.83 & 1.17 \\
\hline & & Female & 31.05 & 0.55 & 54.63 & 1.30 \\
\hline & Ward-3 & Male & 31.85 & 0.75 & 59.75 & 4.78 \\
\hline & & Female & 31.04 & 0.52 & 54.75 & 1.37 \\
\hline & Ward-4 & Male & 31.59 & 0.72 & 59.58 & 1.27 \\
\hline & & Female & 31.49 & 0.63 & 54.78 & 1.34 \\
\hline & Ward-5 & Male & 31.76 & 0.80 & 59.38 & 1.37 \\
\hline & & Female & 31.10 & 0.74 & 54.00 & 1.40 \\
\hline \multirow[t]{9}{*}{40 to 50 years } & Ward-1 & Male & 33.12 & 0.60 & 59.08 & 7.10 \\
\hline & Ward-2 & Male & 32.94 & 0.65 & 60.02 & 1.49 \\
\hline & & Female & 31.90 & 0.68 & 54.87 & 1.14 \\
\hline & Ward-3 & Male & 32.69 & 0.59 & 59.85 & 1.41 \\
\hline & & Female & 31.98 & 0.71 & 55.18 & 1.20 \\
\hline & Ward-4 & Male & 32.75 & 0.62 & 59.77 & 2.04 \\
\hline & & Female & 31.89 & 0.62 & 54.95 & 1.02 \\
\hline & Ward-5 & Male & 32.84 & 0.60 & 60.25 & 1.53 \\
\hline & & Female & 31.88 & 0.69 & 55.12 & 1.03 \\
\hline
\end{tabular}

Table 2: Correlation of innercanthal distance and mesiodistal width of six maxillary anterior teeth $(n=1,200)$

\begin{tabular}{llll}
\hline Parameters & Mean $\pm S D$ & r-value & $p$-value \\
\hline Innercanthal distance $(\mathrm{cm})$ & $31.90 \pm 0.91$ & 0.333 & $<0.001^{\text {** }}$ \\
Mesiodistal width of six maxillary anterior teeth & $57.11 \pm 3.31$ & - & - \\
\hline
\end{tabular}

**There is highly significant correlation between the innercanthal distance and the mesiodistal width of six maxillary anterior teeth in the study population $(p<0.001)$

Table 3: Comparison of the mean of innercanthal distance and mesiodistal width of six maxillary anterior teeth between the two age groups studied

\begin{tabular}{lllll}
\hline & \multicolumn{2}{c}{ Age group } & & \\
\cline { 2 - 4 } Parameters & 18 to 25 years $(n=600)$ & 40 to 50 years $(n=600)$ & t-test & $p$-value \\
\hline Innercanthal distance & $31.405 \pm 0.728$ & $32.395 \pm 0.805$ & 22.3427 & $<0.001^{*}$ \\
Mesiodistal width of six maxillary anterior teeth & $56.78 \pm 3.06$ & $57.43 \pm 3.509$ & 3.4197 & $<0.001^{*}$ \\
\hline
\end{tabular}

*The difference in the mean of both innercanthal distance and mesiodistal width of six maxillary anterior teeth is seen to be extremely statistically significant, suggesting that there is a significant change in these parameters during the aging process
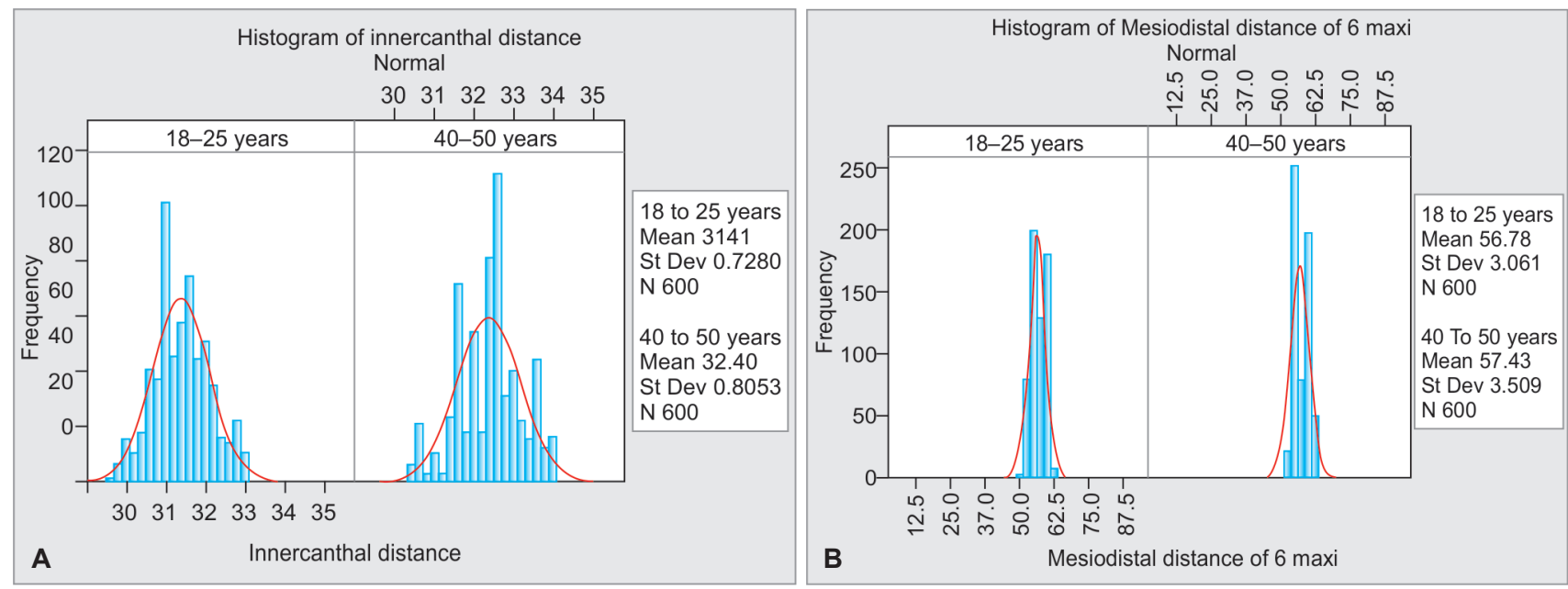

Graphs 1A and B: Age-wise distribution: (A) innercanthal distance; (B) mesiodistal width of six maxillary anterior teeth in the 18 to 25 and 40 to 50 years age group 
Table 4: Comparison of the mean of innercanthal distance and mesiodistal width of six maxillary anterior teeth between the male and female population studied

\begin{tabular}{lllll}
\hline & \multicolumn{2}{c}{ Sex } & & \\
\cline { 2 - 4 } Parameters & Male $(n=600)$ & Female $(n=600)$ & t-test & $p$-value \\
\hline Innercanthal distance & $32.28 \pm 0.8796$ & $31.52 \pm 0.7751$ & 15.8789 & $<0.001^{*}$ \\
Mesiodistal width of six maxillary anterior teeth & $59.44 \pm 3.068$ & $54.77 \pm 1.260$ & 0.0373 & $0.9703^{*}$
\end{tabular}

*The difference in the mean of innercanthal distance is seen to be extremely statistically significant, suggesting that there is a significant difference in the male and female population studied, while in the case of mesiodistal width of six maxillary anterior teeth, the difference of mean was not significant
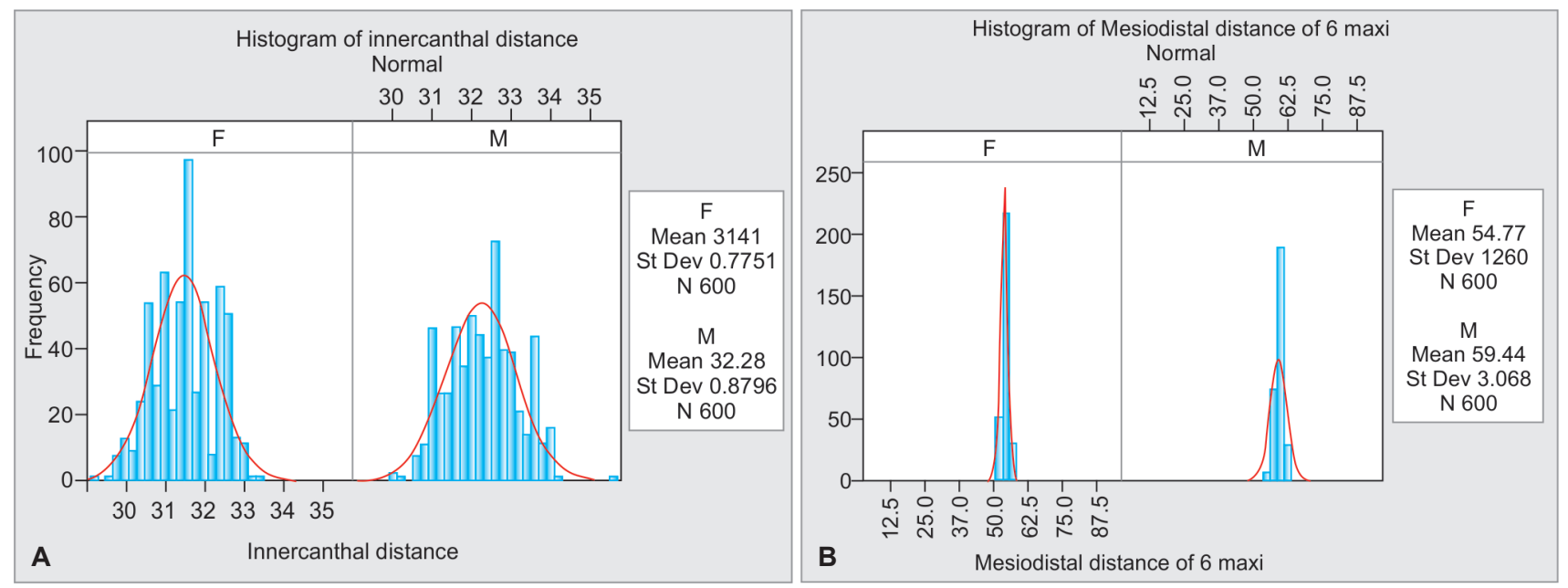

Graphs 2A and B: Sex-wise distribution: (A) innercanthal distance; (B) mesiodistal width of six maxillary anterior teeth

\section{DISCUSSION}

Esthetics is one of the most important factors to be considered while replacing missing maxillary anterior teeth. Every successful rehabilitation must take into consideration the esthetic demands of today's patients, who are very conscious of their appearance and will settle for nothing but the best from their dentist. While replacing the missing maxillary anterior teeth, it is very challenging to replicate the size and position in the absence of any pre-extraction records.

Various anthopometric landmarks has been suggested as an aid in selecting maxillary anterior teeth. Johnson published that different races have different cephalometric norms. This has great implications in the placement and arrangement of teeth and in the evaluation of esthetics in people of dissimilar esthetic origins. ${ }^{7}$ Anthopometric measurements can vary according to ethnic characteristics, as well as age, gender, and even measuring procedure. ${ }^{15}$

Teeth selection is a critical step in determining the outcome of a successful prosthodontic treatment. No definite guidelines for the selection of maxillary anterior teeth pertaining to the Thrissur, Kerala, population exist.

Innercanthal distance is the distance between the medial angles of the palpebral fissure of each eye. Anthopometrically, it is endocanthion bilaterally. ${ }^{16}$ Laestadius ${ }^{17}$ reported that in $78 \%$ of the population, by the 1st year of age, innercanthal growth is achieved, after which the growth in this area is slow in contrast to the outer orbital dimension. At 5 years of age, $93 \%$ of development is achieved, and by 8 to 11 years of age, maturity of this landmark is achieved and does not change significantly after this time. ${ }^{18,19}$ It can be identified and located easily.

The study was conducted to evaluate whether innercanthal distance can be used as a guide in determining the mesiodistal dimension of six maxillary anterior teeth in the Thrissur population and whether this landmark undergoes any dynamic changes as a result of aging. The study also compared whether there was a gender difference in the analyzed facial and dental proportions in this population.

In this study conducted on 1,200 subjects, a very high statistical significance was found in $(n=600)$ females between innercanthal distance and mesiodistal width of six maxillary anterior teeth. However, no statistical significance was found in males $(n=600)$ between the two parameters.

Vanderlei Luiz Gomes et $\mathrm{al}^{1}$ in a study on 81 Brazilian subjects showed that the innercanthal distance showed high probability of being correlated to the mesiodistal width of maxillary anterior teeth.

In this study, the mean innercanthal distance was $32.28 \pm 0.87$ in males and $31.51 \pm 0.77$ in females, and this difference was found to be extremely significant. Freihofer considered a range between 28 and $35 \mathrm{~mm}$ as normal value for this facial structure. ${ }^{20}$ A study conducted by Shibu George and Vinaya Bhat ${ }^{21}$ on 300 South Indian 
patients also showed a gender-based difference in innercanthal distance between males and females. Gender difference in the values of innercanthal distance was also reported by Suryakanth Chhagan Deogade et $\mathrm{al}^{22}$ on a study on 600 subjects in Madhya Pradesh.

Lucas et $\mathrm{al}^{5}$ in Saudi Arabia also found no gender difference in innercanthal distance., and Khalid A Al Wazzan $^{2}$ in a study on 443 subjects in Saudi Arabia found no gender difference in innercanthal width.

In this study, in the 40 to 50 age group (600 subjects), the mean innercanthal distance was $32.39 \pm 0.80$ and in the 18 to 25 age group ( 600 subjects) it was $31.405 \pm 0.72$. The mean mesiodistal width of six maxillary anterior teeth in the 40 to 50 age group and the 18 to 25 age group were $57.43 \pm 3.50$ and $56.78 \pm 3.06$ respectively. Comparative age group-wise evaluation of these two parameters showed an increase with increase in age, and this was extremely statistically significant $(\mathrm{p}<0.001)$.

Abdullah et $\mathrm{al}^{23}$ on a study on 310 subjects in Saudi Arabia found an increase in similar parameters.

No statistical significance was found between males and females while comparing the mesiodistal width of six maxillary anterior teeth $(p=0.97)$, which was $59.44 \pm 3.06$ and $54.77 \pm 1.26$ in this study. A study by Suryakanth Chhagan Deogade et $\mathrm{al}^{22}$ on 600 subjects in Madhya Pradesh also reported no significant differences between the combined mesiodistal width of maxillary anterior teeth of men and women.

These findings suggest that the innercanthal dimension can be used as a preliminary guide for maxillary anterior teeth selection in a Thrissur population. However, additional research on a greater sample involving more parameters is needed.

\section{CONCLUSION}

Within the limitations of this study, the following conclusions can be made - the innercanthal distance was found to have a highly significant correlation in females and not in males; a significant increase was found in the mean innercanthal distance and the mesiodistal width of the six maxillary anterior teeth with increase in age; and the mean innercanthal distance was found to be more in males than in females $(\mathrm{p}<0.001)$ in this population.

\section{REFERENCES}

1. Gomes VL, Gonçalves LC, do Prado CJ, Junior IL, de Lima Lucas B. Correlation between facial measurements and the mesiodistal width of the maxillary anterior teeth. J Esthet Restor Dent 2006;18(4):196-205.

2. Al Wazzan KA. The relationship between intercanthal dimension and the widths of maxillary anterior teeth. J Prosthet Dent 2001 Dec;86(6):608-612.

3. Kern BE. Anthropometric parameters of tooth selection. J Prosthet Dent 1967 May;17(5):431-437.
4. Lang BR. Complete denture occlusion. Dent Clin North Am 2004 Jul;48(3):641-665.

5. Lucas BL, Bernardino-Júnior R, Gonçalves LC, Gomes VL. Distance between the medialis angles of the eyes as an anatomical parameter for tooth selection. J Oral Rehabil 2009 Nov;36(11):840-847.

6. Koury ME, Epker BN. Maxillofacial esthetics: Anthropometrics of the maxillofacial region. J Oral Maxillofac Surg 1992 Aug;50(8):806-820.

7. Johnson PF. Racial norms: Esthetic and prosthodontic implications. J Prosthet Dent 1992 Apr;67(4):502-508.

8. Gonçalves LC, Gomes VL, De Lima Lucas B, Monteiro SB. Correlation between the individual and the combined width of the six maxillary anterior teeth. J Esthet Restor Dent 2009;21(3);182-192.

9. Varjão FM, Nogueira SS. Intercommissural width in 4 racial groups as a guide for the selection of maxillary anterior teeth in complete dentures. Int J Prosthodont 2005 Nov-Dec;18(6): 513-515.

10. Hasanreisoglu U, Berksun S, Aras K, Arslan I. An analysis of maxillary anterior teeth: facial and dental proportions. J Prosthet Dent 2005 Dec;94(6):530-538.

11. Guldag MU, Büyükkaplan US, Sentut F, Ceylan G. Relationship between pterygomaxillary notches and maxillary anterior teeth. J Prosthodont 2010 Apr;19(3):231-234.

12. Varjão FM, Nogueira SS, Filho JN. The center of incisive papilla for the selection of complete denture maxillary anterior teeth in 4 racial groups. Quintessence Int 2008 Nov;39(10):841-845.

13. Latta GH Jr, Weaver JR, Conkin JE. The relationship between the width of mouth, interalar width and interpupillary distance in edentulous patients. J Prosthet Dent 1991 Feb;65(2):250-254.

14. District Census Hand Book. Directorate of Census Operations, Trivandrum, Kerala. Series-33; Census of India; 2001.

15. Lucas BL, Bernardino-Júnior R, Lopes-Júnior I, Gonçalves LC, Gomes VL. Comparison of three anthopometric techniques for tooth selection. Eur J Prosthodont Restor Dent 2012 Jun;20(2):67-70.

16. Koury ME, Epker BN. Maxillary facial esthetics: anthopometric of the maxillary facial region. J Oral Maxillofac Surg 1992 Aug;50(8):806-820.

17. Laestadius ND, Aase JM, Smith DW. Normal inner canthal and outer orbital dimensions. J Pediatr 1969 Mar;74(3);465-468.

18. Hreczko T, Farkas LG, Katic M. Clinical significance of age related changes of the palpebral fissures between age 3 and 18 years in healthy Caucasians. Acta Chir Plast 1990;32(4):194-204.

19. Farkas LG, Posnick JC, Hreczko TM, Pron GE. Growth patterns in the orbital region: a morphometric study. Cleft Palate Craniofac J 1992 Jul;29(4):315-318.

20. Freihofer HP. Inner canthal and interorbital distances. J Maxillofac Surg 1980 Nov;8(4):324-326.

21. George S, Bhat V. Inner canthal distance and golden proportion as predictors of maxillary central incisor width in a south Indian population. Indian J Dent Res 2010 Oct-Dec;21(4): 491-495.

22. Deogade SC, Mantri SS, Sumathi K, Rajoriya S. The relationship between innercanthal dimension and interalar width to the intercanine width of maxillary anterior teeth in central Indian population. J Indian Prosthodont Soc 2015 Apr-Jun;15(2):91-97.

23. Abdullah MA, Stepho HD, Talic YF, Khan N. The significance of inner canthal distance in prothodontics. Saudi Dent J 1997 Jan-Apr;9(1):36-39. 